\title{
Die gebruik van die akoestiese refleks vir bepaling van die gehoorapparaat winsinstelling
}

\author{
Marina Basson, B Log (Pretoria) \\ Departement Spraakwetenskap, Spraakheelkunde en Oudiologie, \\ Universiteit van Pretoria
}

\begin{abstract}
OPSOMMING
Spraakdiskriminasietellings is van twaalf gehoorapparaatdraers met sensories-neurale gehoorverliese verkry. Die toetsstimuli was Afrikaanse eenlettergrepige woorde wat in die teenwoordigheid van agtergrondsgeraas van aaneenlopende spraak met 'n sein-tot-ruis verhouding van +1OdB aangebied is. Spraakdiskriminasietellings is by vier winsinstellings vir elke proefpersoon gemaak, naamlik: ' $n$ winsinstelling wat die akoestiese refleksdrempel vir spraakgeraas ontlok in die oor kontralateraal tot die oor met die gehoorapparaat; twee winsinstellings by $\pm 10 \mathrm{~dB}$ relatief tot die refleks drempel winsinstelling; en 'n winsinstelling waar aaneenlopende spraak teen $50 \mathrm{~dB}$ gehoorpeil vir die pasiënt mees gemaklik klink. Die hoogste gemiadelde spraakdiskrimi-
nasietellings is by die refleksdrempel winsinstelling verkry.
\end{abstract}

\section{ABSTRACT}

Aided speech discrimination scores were obtained for twelve subjects with sensori-neural hearing loss. The test stimuli were Afrikaans monosyllabic words with a competing message of connected discourse at a signal-to-noise ratio of $+10 d B$. Measurements of speech discrimination were made at four gain settings for each subject: a gain setting which elicited the acoustic reflex threshold for speech noise in the ear contralateral to the aided ear; two gain settings at \pm lOdB relative to the reflex comfortable for him. Mean speech discrimination the subject evaluated connected speech at 50dB HL until it sounded most

Dit is 'n bekende feit dat gehoorapparaatseleksieprosedures gebruik maak van die subjektiewe beoordelings van die pasiënt, en sluit gewoonlik suiwertoon, lug- en beengeleidingstoetse, spraakoudiometrie en die bepaling van die pasiënt se mees gemaklike luidheid (MGL) en verdrabare peil (VP) in. ${ }^{12}$ In die geval van jong kinders en moeilik toetsbare pasiënte is bogenoemde prosedures ontoereikend, aangesien sodanige pasiënte nie in staat is om betroubaar op 'n ouditiewe sein te reageer nie. Die gevolg is dat gehoorapparaatseleksie op grond van onvolledige en onbetroubare oudiometriese inligting uitgevoer moet word. ${ }^{9}$

Om bogenoemde redes is daar in dié navorsing begin om die akoestiese refleks (AR) te gebruik as 'n hulpmiddel tydens meer objektiewe gehoorapparaatseleksie. Die pasiënt maak dan nie enige subjektiewe beoordelings nie. In 'n studie wat uitgevoer is deur Rappaport en Tait," gebruik hulle die akoestiese refleksdrempel (ARD)-meting om die wins van die gehoorapparaat in te stel. Sodoende het hulle die verhouding tussen die ARD en maksimum spraakdiskriminasie by gehoorapparaatdraers ondersoek. Hulle vind dat die hoogste gemiddelde spraakdiskriminasietellings by die ARD-winsinstel ling verkry is in vergelyking met 'n MGL-winsinstelling, en winsinstellings $10 \mathrm{~dB}$ bo en onder die ARD-instelling. Uit hulle navorsing wil dit dus voorkom asof die oudioloog die wins van die gehoorapparaat moet instel by ' $n$ intensiteitspeil wat die ARD ontlok. Hierdie studie is 'n poging om bogenoemde bevindings te bevestig.

\section{METODE}

PROEFPERSONE

'n Eksperimentele groep van 12 volwasse Afrikaanssprekende gehoorgestremde persone is geselekteer. Die pasiënt het reeds gehoorapparate ontvang by die Oor-, Neuș- en Keelhospitaal in Pretoria. Alle proefpersone moes 'n geringe of ' $n$ gemiddelde sensories-neurale gehoorverlies vertoon (gemiddelde suiwertoondrempel van die beter oor tussen $27 \mathrm{~dB}$ en $55 \mathrm{~dB}$ ). ${ }^{10}$ Sodra die gehoorverlies bo dié kriteria toeneem, of konduktief van aard is, word die moontlikheid minder dat die AR geregistreer kan word. ${ }^{7}$ Laasgenoemde was dan 'n vereiste vir die uitvoering van die eksperiment. Elke proefpersoon het sy gehoorapparaat reeds vir 'n tydperk van ses maande tot 'n jaar gedra.

\section{STIMULI}

Gepulseerde spraakgeraas teen 50dB gehoorpeil (GP), vanaf 'n GSI 10 oudiometer, is gebruik om die ARD-winsinstelling te bepaal. Dit is gepulseer (een sekonde aantyd, en drie sekondes aftyd), om refleksadaptasie te verhoed." 'n Kassetopname van aaneenlopende spraak teen $50 \mathrm{~dB}$ GP is gebruik vir die bepaling van die MGL-winsinstelling. 
Spraakdiskriminasietellings is bepaal met behulp van die eerste vier Afrikaanse foneties gebalanseerde woordlyste. Elke woordlys bestaan uit 25 eenlettergrepige woorde met hul inleidende frases. Die woordlyste is opgeneem op 'n hoë kwaliteit kassetband in die teenwoordigheid van 'n kompeterende geraas van aaneenlopende spraak. ${ }^{6}$ Die sein-tot-ruis verhouding was $+10 \mathrm{~dB}$. Die kompeterende geraas is ingesluit, omdat geraas dikwels aanwesig is in die kommunikasieomgewing. ' Dit gee dus ' $n$ beter beeld van die diskriminasievermoë van 'n persoon in alledaagse kommunikasiesituasies.

\section{EKSPERIMENTELE PROSEDURE}

Elke proefpersoon is in 'n klankdigte kamer, op 'n stoel, 1,5 meter vanaf die oudiometer se luidspreker geplaas, en het direk na die luidspreker gekyk. "Daarna is die volgende prosedure by elkeen gevolg:

\section{Bepaling van die $M G L$-winsinstelling}

Terwyl die proefpersoon na 'n kassetopname van aaneenlopende spraak teen 50dB GP (verteenwoordigend van die intensiteit van alledaagse gesprek') oor die luidspreker geluister het, het hy/sy die winskontrole van die gehoorapparaat verstel, totdat die spraak "mees gemaklik" geklink het. Hierdie instelling is op die winskontrole gemerk en winsinstelling A genoem.

\section{Bepaling van die $A R D$-winsinstelling}

Die meetprop van die elektro-akoestiese impedansbrug is in die kontralaterale oor geplaas. Terwyl die proefpersoon na die gepulseerde spraakgeraas oor die luidspreker teen $50 \mathrm{~dB}$ GP geluister het, het die ondersoeker die winskontrole van die gehoorapparaat verstel, totdat die punt gevind is waar die kleinste waarneembare defleksie van die balansmeternaald, kenmerkend van die ARD, waargeneem is. ${ }^{4,}$ " Hierdie posisie op die winskontrole is gemerk, en winsinstelling $\mathbf{B}$ genoem.

\section{Bepaling van die winsinstellings: $10 \mathrm{~dB}$ bo en $1 O \mathrm{~dB}$ onder die ARD-winsinstelling}

Die gehoorapparaat is vervolgens in 'n Fonix FP 20 gehoorapparaat analiseerder geplaas wat die uitset van die gehoorapparaat by die ARD-win'sinstelling weergegee het. Hierdie KDPwaarde het gedien as 'n verwysingspunt waarvandaan die winskontrole verstel is na 'n winsinstelling van $10 \mathrm{~dB}$ bo en $10 \mathrm{~dB}$ onder die ARD-winsinstelling. Dié winsinstellings is op die kontrole gemerk, en winsinstellings $C$ en $D$ genoem. Bogenoemde winsinstellings is ingesluit, ten einde vas te stel of spraakdiskriminasietellings van gehoorapparaatdraers verander binne die intensiteitsomvang van $-10 \mathrm{~dB}$ en $+10 \mathrm{~dB}$, relatief
tot die ARD."

\section{Spraakdiskriminasietoetsing}

'n Spraakdiskriminasietoets is vervolgens by elk van die vier winsinstellings uitgevoer. Die kasset-opname van die woordlyste, in die teenwoordigheid van die kompeterende geraas, is oor die luidspreker aangebied. Die woordlyste is teen $50 \mathrm{~dB}$ $\mathrm{GP}$, en die kompeterende geraas teen $40 \mathrm{~dB}$ GP aangebied. Die persentasie spraakdiskriminasie is by elke winsinstelling bereken.

\section{RESULTATE}

Die gemiddelde en omvang van spraakdiskriminasietellings(\%) van die 12 proefpersone, by die vier winsinstellings, is bereken. "Dit word in Tabel I, hieronder, weergegee.

Dit blyk dat daar groot individuele verskille asook oorvleueling van spraakdiskriminasietellings by die vier winsinstellings is. Die hoogste gemiddelde spraakdiskriminasietellings is egter verkry by winsinstelling B (ARD-winsinstelling).

Toepassing van die metode van meervoudige vergelyking, ${ }^{3}$ toon egter dat bogenoemde spraakdiskriminasiestellings nie betekenisvol hoër is as die van die spraakdiskriminasiestellings wat by winsinstelling A (MGL-winsinstelling) verkry is nie.

Met betrekking tot verdere onderlinge verskille tussen die spraakdiskriminasietellings by die vier winsinstellings, is die volgende gevind tydens uitvoering van Friedman se rangsomtoets: ${ }^{13}$

- Spraakdiskriminasietellings by winsinstelling B is betekenisvol hoër as dié verkry by winsinstelling $C$.

- Spraakdiskriminasietellings by winsinstelling B is betekenisvol hoër as dié verkry by winsinstelling $\mathrm{D}$.

- Daar is nie ' $n$ beduidende verskil tussen die spraakdiskriminasietellings by winsinstellings $C$ en $D$ nie.

\section{BESPREKING}

Die feit dat die hoogste gemiddelde spraakdiskriminasietellings (in geraas) by winsinstelling B verkry is, bevestig die reeds genoemde bevindinge van Rappaport \& Tait. "Moontlike verklarings vir dié bevinding kan onttrek word uit studies gedoen deur onder andere Borg ${ }^{2}$ en Lidén, Nordlund en Hawkins. ${ }^{5}$

Borg ${ }^{2}$ vind dat die sametrekking van die stapediusspier by die ARD, lae frekwensie energie (onder $100 \mathrm{~Hz}$ ) meer attenueer as die van hoë frekwensie. Volgens Lidén et al. ${ }^{5}$ is bogenoemde eienskap van die AR van waarde vir die persoon wat na spraak in die teenwoordigheid van lae frekwensie agtergrondgeraas

Tabel 1 Die gemiddelde en omvang van spraakdiskriminasietellings (\%) van die 12 proefpersone, by die vier winsinstellings

\begin{tabular}{|l|c|c|}
\hline Winsinstelling & Gemiddelde spraakdiskriminasie (\%): & Omvang van spraakdiskriminasie- \\
tellings (\%)
\end{tabular}

Die Suid-Afrikaanse Tydskrif vir Kommunikasieafwykings, Vol. 30, 1983 
luister. Die AR stel die persoon dus in staat om die spraakfrekwensies bo $1000 \mathrm{~Hz}$ (wat meer inligting bevat as die frekwensies onder $1000 \mathrm{~Hz}$ ) beter te hoor.

Die bevinding dat daar nie 'n betekenisvolle verskil bestaan tussen die spraakdiskriminasietellings by winsinstellings A en B nie, kan moontlik toegeskryf word aan die feit dat die proefpersone reeds ondervinding van die dra van 'n gehoorapparaat het. Hulle het moontlik al geleer om die wins van die apparaat self in te stel by ' $n$ vlak wat vir hulle maksimum spraakdiskriminasie gee. ${ }^{14}$

Niemeyer ${ }^{8}$ gee 'n moontlike verklaring vir die bevinding dat die spraakdiskriminasietellings by winsinstelling B betekenisvol hoër is as dié verkry by winsinstelling $C$. Hy meen dat spraakdiskriminasie afneem by intensiteitsvlakke bo die ARD, weens sensoriese oorlading. Dit lei tot distorsie van spraak, en gevolglike afname in die spraakverstaanbaarheid.

Die feit dat spraakdiskriminasietellings verkry by winsinstelling B ook betekenisvol hoër is as dié by winsinstelling D, word deur Rappaport en Tait ${ }^{\text {ll }}$ verklaar. Hulle is van mening dat die spraaksein by ' $n$ intensiteitsvlak onder die ARD, nog nie hard genoeg is om maksimum verstaanbaarheid mee te bring nie. Die kompeterende boodskap in die agtergrond mag ook dele van die stimuluswoorde maskeer.

Uit bogenoemde bespreking word afgelei dat spraakdiskriminasietellings in geraas, met 'n gehoorapparaat, betekenisvol toeneem met intensiteitstoename, totdat die ARD bereik word. Met 'n verdere toename in intensiteit neem die spraakdiskriminasie tellings weer betekenisvol af.

Addisionele inligting wat op grond van subjektiewe beoordelings van die proefpersone verkry is, is dat die ARD-winsinstelling by ' $n$ intensiteitspeil voorkom wat naby of by die peil is wat vir die persoon mees gemaklik klink, eerder as by 'n peil wat die persoon se verdrabare peil aandui.

\section{GEVOLGTREKKINGS}

Hierdie studie dui op 'n positiewe verband tussen maksimum spraakdiskriminasie in geraas, met 'n gehoorapparaat, en die ARD-winsinstelling. Hierdie verband het kliniese toepassingsmoontlikhede in dié sin dat die oudioloog die ARDmeting kan gebruik as 'n objektiewe meting vir die bepaling van die winsinstelling van die gehoorapparaat.

Dit is veral in die geval van pediatriese en moeilik toetsbare pasiënte wat dié objektiewe meting vir die bepaling van die gehoorapparaatwinsinstelling van nut is.

Aangesien die rol van die akoestiese refleks in gehoorapparaatseleksieprosedures nog in sy ontwikkelingstadium is, word verdere navorsing in dié rigting verwelkom, met die oog op die verbetering van bestaande prosedures. Navorsers kan in jié rigting aangespoor word deur die woorde van Horning 1975) wat deur Northern aangehaal word:

zn increasing number of mild and moderate hearing-impaired voungsters who previously would have been unaidable, ... are successfully wearing and benefiting from aids selected on the basis of acoustic reflex measurement. ${ }^{9}$

\section{BEDANKINGS}

Die outeur spreek haar dank uit teenoor Prof. I. S. Hay en Mev S. Meyer van die Departement Spraakwetenskap, Spraakheelkunde en Oudiologie van die Universiteit van Pretoria, onder wie se leiding hierdie studie uitgevoer is, asook teenoor Mev G. de Villiers, van die Departement Statistiek, vir die statistiese verwerking van die data.

\section{VERWYSINGS}

1. Alpiner, J. G. (1975): Hearing Aid Selection for Adults. In: M. C. Pollack (Ed.) Amplification for the HearingImpaired. New York: Grune \& Stratton.

2. Borg, E. (1969): A Quantitative Study of the Effect of the Acoustic Stapedius Reflex on Sound Transmission through the Middle Ear of Man. Acta oto-laryngologica, $66,461-472$.

3. Gibbons, J. D. (1976): Nonparametric Methods for Quantitative Analysis. New York: Holt Rinehart \& Winston.

4. Jerger, S. \& J. Jerger. (1977): Diagnostic Value of Crossed vs Uncrossed Acoustic Reflexes. Archives of Otolaryngology, 103, 445-453.

5. Lidén, G., B. Nordlund \& J. E. Hawkins, jr. (1963): Significance of the Stapedius Reflex for the Understanding of Speech. Acta oto-laryngologica, supplement 188, 275-279.

6. Martin, F. N. (1975): Introduction to Audiology. Englewood Cliffs, N. J.: Prentice-Hall, Inc.

7. Mc Candless, G. A. \& R. W. Keith. (1980): The Use of Impedance Measures in Hearing Aid Fitting. In: J. Jerger (Ed.) Clinical Impedance Audiometry. (Second Edition). N. J.: American Electromedics Corp.

8. Niemeyer, W. (1971): Relations Between the Discomfort Level and the Reflex Threshold of the Middle Ear Muscles. Audiology, 10, 172-176.

9. Northern, J. L. (1978): Hearing Aids and Acoustic Impedance Measurements. Monographs in contemporary Audiology, 1:2, 5-23.

10. Quigley, S. P. (1978): Effects of Early Hearing-Impairment on Normal Language Development. In: F, N. Martin (Red.) Pediatric Audiology. Englewood Cliffs, N. J.: Prentice-Hall, Inc.

11. Rappaport, B. Z. \& C. A. Tait. (1976): Acoustic Reflex Threshold Measurements in Hearing Aid Selection. Archives of Oto-laryngology, 102, 129-132.

12. Shapiro, I. (1976): Hearing Aid Fitting by Prescription. Audiology, 15:2, 163-173.

13. Steyn, A. G. W., C. F. Smith \& S. H. C. du Toit. (1982): Moderne Statistiek in die Praktyk. (Tweede uitgawe) Pretoria: J. L. van Schaik.

14. Yantis, P. A., J. P. Millin \& I. Shapiro. (1966): Speech Discrimination in Sensori-Neural-Hearing Loss: Two Experiments on the Role of Intensity. Journal of Speech and Hearing Research, 9:2, 187-193. 
Automatic and Manual Screening and Clinical Audiometers and
Impedance Meters

Viennatone computerised Micro-Processor Clinical Audiometer

Before you start your own practice, and before you think of buying your own equipment, please contact us for best prices, terms or leasing

We manufacture Soundproof Booths and Soundproof Rooms

Industrial Noise Consultants

\section{HEARING AIDS}

We specialise in

The supply and fitting of Hearing Aids for all hearing losses,
especially for:

Nerve Deafness

Recruitment

Bone Conduction cases

CROSS AIDS: Cros - Bicros - Multicros, etc.

BONE CONDUCTION AIDS for Body, Earlevel, Glasses (Speciality by Viennatone).

BINAURAL FITTINGS. We import and stock: Viennatone, Qualitone, Microson, Amplivox and Willco hearing aids.

MOULDS: Soft, hard, skeleton, vented, occluded, etc.

REPAIRS: All aids supplled with a scientific performance report after repair.

\section{TINNITUS MASKERS and TINNITUS INSTRUMENTS}

SPECIAL PRICES for Dealers and Institutions.

Now agent for Siemens Hearing Aids and Infrared Teaching Equipment 